\title{
Frizzled-related Protein assoziiert mit Typ-2-Diabetes-Risiko
}

Fragestellungen: Fördert das Protein SFRP5 Prädiabetes undTyp-2-Diabetes? Und haben Adipositas oder andere klinische Faktoren einen Einfluss darauf?

Hintergrund: Das SFRP5-Protein (secreted frizzled-related protein 5) gehört zu einer Familie von Proteinen, die den WnT(Wingless und Int) Signaltransduktionsweg bilden, durch den Zellen auf äußere Signale reagieren können. Das Protein wird von viszeralem, subkutanem und perikardialem Fett sezerniert sowie von Leber, Herz, Lymphozyten und Pankreasinselzellen. Im Tiermodell ist der Verlust von SFRP5 mit einer gestörten Glukosetoleranz und Insulinresistenz assoziiert. Im Mausmodell werden vermehrt Makrophagen und proinflammatorische Proteine im Fettgewebe gefunden. Interessanterweise geht der Verlust des SFRP5-Proteins auch mit einer höheren Wahrscheinlichkeit für Mykardinfarkte und ein größeres Infarktareal mit erhöhten proinflammatorischen Markern darin einher. Beim Menschen sind die Ergebnisse dagegen kontrovers. In Beobachtungsstudien konnten sowohl positive als auch inverse und vollkom-

Originalie

Carstensen-Kirberg $\mathrm{M}$, Kannenberg JM, Huth C et al. Inverse associations between serum levels of secreted frizzled-related protein-5 (SFRP5) and multiple cardiometabolic risk factors: KORA F4 study. Cardiovasc Diabetol. 2017 Aug 29;16(1):109. doi: 10.1186/ s12933-017-0591-x. men fehlende Assoziationen des Proteins bzgl. Diabetes und Insulinresistenz gefunden werden. In klinischen Studien wurde ein inverser Zusammenhang von SFRP5 mit dem Auftreten des metabolischen Syndroms und der Schwere einer KHK dargestellt. Epidemologische Studien fehlen.
Patienten und Methoden: SFRP5-Serumspiegel wurden bei 1.096 Teilnehmern der KORA-F4-Studie im Alter zwischen 62 und 61 Jahre analysiert. Der Zusammenhang mit kardiometabolischen Risikofaktoren, Prädiabetes und Typ-2-Diabetes wurde untersucht. 666 Teilnehmer hatten Prä- oder Typ-2-Diabetes. Mithilfe multivariater Regressionsanalysen wurden die Zusammenhänge auf potenzielle Einflussfaktoren wie Alter, Geschlecht, Body Mass Index, Lebensstilfaktoren, Lipidwerte, Bluthochdruck, Nierenfunktion und Myokardinfarkt getestet.

Ergebnisse: Höhere SFRP5-Spiegel sind mit niedrigerem $\mathrm{HbA}_{1 \mathrm{c}}$, BMI, systolischem Blutdruck, GFR und CRP-Spiegeln als auch HDL und Adiponektin im volladjustierten Modell assoziiert $(\mathrm{p}<0,009)$. Der Zusammenhang mit Blutzuckerwerten, Insulin, Insulinresistenz und allgemein kardiometabolischen Risikofaktoren wurde durch Adjustieren mit dem BMI überdeckt. Die SFRP5-Spiegel waren geringer bei Teilnehmern mit Präund Typ-2-Diabetes im Vergleich zu stoffwechselgesunden Probanden. Im volladjustierten Modell waren höheren SFRP5-Spiegel mit einem geringeren Risiko für Prä-/Diabetes assoziiert. Jede Verdopplung der SFRP5-Spiegel ging mit einer 30\%igen Reduktion des Diabetesrisikos einher.

Schlussfolgerungen: Höhere SFRP5-Spiegel sind invers mit verschiedenen Risikofaktoren für Typ-2-Diabetes und Herz-Kreislauf-Erkrankungen assoziiert. Der BMI ist allerdings ein starker Co-Founder, aber summa summarum geht ein hoher SFRP5-Spiegel mit einem niedrigeren Risiko für Prä- und Typ2-Diabetes einher. SFRP5 ist damit ein Kandidat für einen neuen Biomarker im Kontext der Prävention von Diabetes mellitus und kardiovaskulären Erkrankungen.

\section{- Kommentar von Prof. Dr. med. Peter E. H. Schwarz}

\section{Es zahlt sich aus, epidemiologische Kohorten zu haben}

Toll! SFRP5 verhindert Diabetes oder SFRP5 bremst einen Pathomechanismus der zu Diabetes führt. Ähnlich wie Adiponektin scheint das ein protektives Peptid zu sein. Inwiefern der WnT-Signaltransduktionsweg Diabetes verhindern kann, muss weiter untersucht werden, aber nichtsdestotrotz könnte ein solches Protein zukünftig im Rahmen eines Screenings Risikopersonen identifizieren. So etwas brauchen wir, da uns solche Biomarker in die Lage versetzen zu agieren. Ob uns SFRP5 hilft, einen neuen Pathomechanismus zur Diabetesentstehung zu identifizieren, oder ob der Mechanismus auch Konsequenzen für die Therapie hat, ist noch unklar. Aber in dieser Studie zahlt es sich aus, vor 10 bzw. 20 Jahren angefangen zu haben, epidemiologische Kohorten aufzubauen. Diese helfen uns heute, wichtige wissenschaftliche und klinische Fragen anzugehen und zu klären. Die Quintessenz: SFRP5 ist ein Marker für Diabetesrisiko und führt vielleicht zu einem neuen Verständnis von Diabetes mellitus Typ 2.

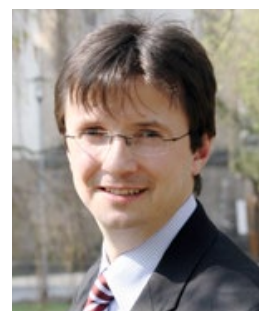

Prof. Dr. med. Peter E. H. Schwarz

Med. Klinik III, TU Dresden, Fetscherstraße 74, 01307 Dresden und Paul Langerhans Institut Dresden, German Center for Diabetes Research peter.schwarz@uniklinikum-dresden.de 